\title{
Short Film Experience: Introduction
}

Pepita Hesselberth, Assistant Professor Film and Literary Studies, Leiden University Centre for the Arts in Society (LUCAS), Leiden University

Carlos M. Roos, Centre for Cinema and Media Studies CIMS, Ghent University; Institute for Philosophy, Leiden University

\section{Copyright Notice:}

The present text was originally published as the editorial of Empedocles: European Journal for the Philosophy of Communication vol. 5 (2015), pp. 3-12. Copyright P. Hesselberth and C.M. Roos. It is basically the same post-print version sent to Intellect LTD (publisher), except that bibliographical references have been corrected. This material is made public via Green Open Access. Contributors to all Intellect journals can deposit their post-print file in institutional repositories or on a personal website. Post-print refers to the version of the paper after peer-review, with revisions having been made but before copy-editing and typesetting have taken place. There is no embargo period so authors can post files as soon as the article has been published. Full text version of the article on IngentaConnect:

http://www.ingentaconnect.com/content/intellect/ejpc/2015/00000005/F0020001/art00001

For purposes of citation, please refer to the journal version: Hesselberth, P. and Roos, C.M. (2015), 'Short Film Experience: Introduction', Empedocles: European Journal for the Philosophy of Communication 5: 1+2, pp. 3-12, doi: 10.1386/ejpc.5.1-2.3_2 


\section{Short Film Experience: Introduction}

Pepita Hesselberth, Assistant Professor Film and Literary Studies, Leiden University Centre for the Arts in Society (LUCAS), Leiden University

Carlos M. Roos, Centre for Cinema and Media Studies CIMS, Ghent University; Institute for Philosophy, Leiden University

Towards the end of The Evolution of Film (2007), film scholar Janet Harbord describes the following situation.

Walking through the concourse of a London station, a straggle of people is bunched more or less in a row, facing the same direction. Their gaze is directed towards the electronic information panels with travel details of destinations, train times and platforms. To the right a different panel attracts attention [...] carrying an assortment of news, advertising and weather reports. But at the instant in which I look up there are the figures of Laurel and Hardy. They carry a ladder, but as Laurel shifts position, turns direction, the ladder swings haphazardly into the back of Hardy. He lurches forward in exaggerated pantomime. The gag is familiar, predictable, and yet nostalgically entrancing. Despite the surrounding soundscape of platform announcements, trains on the move, mobile phone conversations, the exchanges of commerce in the near food outlet, the gestural language of the film effectively communicates. (2007: $131-32)$

The clip, which turns out to be a commercial in which the fragment of a slapstick is reappropriated, captures the author's attention (and with hers that of many around her) on 
account of its specific cinematic qualities: its thickening of time ('a past crashing in on the present'), its attempt at narrative ('its comedy, its theme of the accidental, $[\ldots]$ its gestural ability to communicate in an environment of sound distraction') and its affective appeal, at once reassuring of a pleasurable experience and retaining the threat of disruption of that experience (2007: 132). The fragment is compelling, moreover, and above all, we would like to suggest, because it is short, sufficient unto itself, somehow distinct from the ongoing stream of otherwise unrelated sounds and images.

Since the advent and standardization of the theatrical feature length film, the audiovisual short has been more or less marginalized in the discussions on cinematic experience. Historically stretching from the 'early cinema' of the vaudeville, to the now obsolete 'little films' of YouTube and beyond, the audio-visual short traverses a wide variety of media platforms, practices and technologies, including animation, video installation art, video clips and TV commercials, as well as animated GIFs, machinima and DIY movies, made to measure for handheld devices. The widespread usage of the format suggests that short audiovisual artefacts are not an anomaly or rarity on the periphery of cinema, but rather should be put at the centre of our discussions when rethinking cinematic experience and the moving image today. Such is the request we have made to the contributors to this volume: to write a short essay on short film experience.

In philosophy, the possibility of duration is attributed to the interplay between the intelligible structure of events and the cognitive structure of their witnesses. Thus, in Harbord's suggestive example, the advertisement can be perceived as a temporal event thanks to the specific characteristic of the clip on the screen itself, and the physiological/ psychological machinery involved in its reception. The preponderance granted to any of the two poles defines standpoints on duration that echo key confrontations in metaphysics, 
epistemology and philosophy of mind - e.g. between realism and idealism, objectivism and subjectivism, or externalism and internalism. The proximity to any one end of the spectrum is seldom extreme; therefore, it is common to ground duration on the equitable relation between events and witnesses, or, in the case of the cinematic, between film and viewer, exhibition and visitor, screen and interactant. It is this tendency to relate and intertwine objects-as-such and subjects-as-such (as known in the philosophical parlance) that informs the articles in this volume. Experience, here, becomes the level of analysis. As something that elapses, the audio-visual production finds itself at home in the theoretical domains of duration, which is a fundamental of time experience (Pöppel 1978) worked out extensively in the history of western thought. In other words, dealing with shortness and duration when dealing with audio-visual artefacts means, inextricably, dwelling on the cinematic as an encounter between technologically mediated sounds and images and the participating viewer that engages with them. A focus on the cinematic as an encounter, Hesselberth has argued elsewhere, intimates a focus on the dialogic relationship between the participating viewer and the concrete cinematic environment he or she inhabits (2014). The articles collected in this volume are linked in that they approach various kinds of short audio-visual artefacts from the point of view of such a dialogic relationship, thus elaborating on a conception of the cinematic both in and beyond the classical movie theatre.

The consensual preoccupation of the authors with time, creativity, perception and technology - topics of paramount importance for film theory and philosophy alike - suggests their status as nodal points in both theoretical reflections on, and concrete articulation of, the moving image today. The intellectual intersections offered here are determined by their specific historical and cultural coordinates, and therefore should not be seen as a universal panacea. Nonetheless, they stand out as useful points of departure for analytical and critical 
ventures upon the cinematic, inasmuch as they facilitate the identification of consonances and dissonances among theoretical perspectives and their rapport with actual states of affairs. Moreover, the cases dealt with in this volume give us an insight into a wide range of cinematic practices and experiences qua communicational experience, as concerns the metaphysics of its medium, the shaping of its discourses, the sensory reception of its content and the affordances of its instruments.

Transgressing the boundaries between media forms and practices while paying tribute to their specificity, short films challenge the borders of the disciplines that study them, thus urging us to confront questions regarding the conditions of moving-image production (technological affordance, creative process), and the configurations of time, space and the self (time/space formations, perceptible materiality) that lay at the heart of cinematic experience. Throughout this volume, different manners of theorizing shortness are represented in an array of discursive styles, and from various disciplinary backgrounds. What these essays all have in common, however, is that they give primacy to theoretical reflection over empirical enquiry without severing praxis from the core of the debate. To phrase it differently, where the viewer's engagement with the cinematic is approached in relational terms, so is the scholar's engagement with practice and theory, as new and old cinematic phenomena are placed in dialogue with the theories and conceptual frameworks employed to study them.

In so doing, the philosophical generality of the aforementioned topics is conveniently revisited, explicitly or implicitly, form the standpoint of cinematic experience. The articles offer cutting-edge interventions within the respective fields of media archaeology, film philosophy and critical theory that come to enliven classic philosophical debates, while providing sound insights into the culture of the moving image today through a sustained focus on cinematic concision. Hence, the present issue not only informs us of the wide sense in 
which the cinematic can be construed, far beyond celluloid and the movie theatre, but is also suggestive, by its very act of inclusion, of the diversity of assumptions as to what 'shortness' might entail and how it relates to specific audio-visual entities or events.

Any division of the contributions into sections will necessarily fall short of both the richness of the individual pieces and their intricate intertwinement around the notions of time, creativity, perception and technology. We have nonetheless made an attempt at arranging the articles in such an order so as to allow for a productive assessment of resemblances and divergences in the way the notion of cinematic concision is addressed (while necessarily leaving out others that are nonetheless there). The first four articles, each in their own manner, ask the question: what makes for a (good) short film? They do so from the point of view of a practice-based enquiry, combining academic exertion with insights gained through the authors' endeavours as film-makers, film/art critics and/or curators. Of these four articles, two, moreover, explicitly reflect on the linkage between making a short film and writing a short essay (Bal and Cahill/Vuillermoz).

In the essay that opens this volume, renowned cultural theorist, critic and video artist Mieke Bal addresses shortness in terms of the processes of cinematic creation, where shortening stands out as the shaping gesture of selecting 'what is more important'. What is most important when making a film short, for Bal, is the balancing act between exposition and narrative (or showing and telling if you will), both considered as a means to build an argument. This amounts to a content-driven articulation of discourse based on existing material. The author dwells on two creative strategies: one is the decomposition of a whole into shorter discursive units; the other is the assemblage of audio-visual parts towards a meaningful whole. These strategies play on the level of running time, that is, they deal with duration as an intrinsic quality of the footage. On the receptive end, however, Bal suggests 
that it is not only chronometric length that determines the perception of shortness. The conditions of exhibition play an equally important role, as she illustrates by referring to the case of video art, making a productive distinction between the theatrical short from the gallery short. The spatial set-up in which such works are shown reflect on the engagement of the public, whose decisions as to what to watch and for how long becomes a crucial parameter of the experience, and, as such, of the work itself. Thus, different spaces propitiate different visual attitudes.

Intentions and attitudes are interesting lines of enquiry that reappear consistently throughout this volume. In film critic and scholar Adrian Martin's piece, for instance, visual attitudes and authorial intentions crystallize through the tension between not showing and telling, but content and form. For him, it is the reinforcing balance between the two (as also stipulated by Bal) that is suggested to be the most salient characteristic of a good short. In other words, it is the temporal condensation of their struggle what makes for cinematic shortness. Interestingly, the notion of brevity, here, is neither referential (against feature films) nor metrical (against the clock), but immanent to the cinematic material. In addressing duration this way, Martin's evaluative principle recalls prevalent debates in aesthetics and communication theory regarding concept and form, as well as ontological discussions about the interplay between idea and substance. In these considerations, short films stand out as a crucial moment of contemporary cinematic creativity, emerging out of a strategy of assemblage.

Early film scholar and cultural critic James Leo Cahill contributes to this volume with a straightforward translation of, and introduction to, Émile Vuillermoz' short essay 'Concision' from 1929. Originally conceived for the press, Vuillermoz' piece makes it plain that the concerns of Bal, Martin and others (in this special issue and elsewhere), as to the 
normative character of the feature length narrative film, are by no means something novel. The article permits of both a historical reading concerning the cinematic material and its theorization during the early twentieth century, as well as a transposition into the digital aesthetics practices prevalent today. As introduced by Cahill, Vuillermoz's reflections on cinematic concision - i.e. on 'films reduced to their essential elements' - allow for the sharpening and amplification of the moving image (productive strategy) in ways that directly impact the cinematic experience (receptive attitude). Here, curiosity and enchantment stand out as mental states that promote the audience's engagement without mesmerizing effects.

In a bold and provocative move, curator and film scholar Edwin Carels takes the reader even one step further back into the past by revisiting some of cinema's forgotten prehistories while posing the question, 'how short can a short film be?' - a point at which the discussion acquires a philosophical tenor while remaining within the domains of media archaeology. Carels' answer entails looking into a series of pre-cinematic technologies in which no more than two dissimilar images are combined to generate the suggestion of motion. Shortness is pondered carefully vis-à-vis the ontology of the cinematic artefact and machinery past and present, without disregard to the possibilities that cinematic technologies afford at different moments in history. Underlying the argument is the suggestion that state-of-the-art animation is not really all that different from its earliest predecessors when it comes to its primary qualities, particularly with regard to motion, number and figure. As such, the essay indirectly invites to a refreshing takes on landmark metaphysical discussions in the rationalist and empiricist traditions.

The next four articles are linked in that they all offer a variation on the theme of repetition and difference (a theme that is further revisited in Poulaki's considerations on the 
loop, below) by dwelling on one specific audio-visual practice or artefact: the remake, the music video, the actuality and the flicker film.

Building on the line of enquiry set out in his Philosophy and the Moving Image (Mullarkey, 2010), film philosopher John Ó Maoilearca asks what remains of what he there calls the Élan Cinematique in the five remakes of Det perfekte Menneske/The Perfect Human (Leth, 1967) that make up De fem benspaend/The Five Obstructions (Leth \& Von Trier, 2003). Referring to the brain 'as an organ of mime' that performs ideas via their articulation, Ó Maoilearca argues that such a performative gesture permits time (and space) to emerge from both original and remade films. The relation between remaking and creating stands out here as a powerful interplay that helps understanding artistic and philosophical production, in terms of its relational value (originality) and its ontology (the discursive entity being remade/ created). From a Bergsonian perspective, it allows for useful distinctions and connections between the idea as philosophical intuition and the image as its discursive 'shadow'. The two relate insofar as, first, the image does project the idea (on-screen or otherwise), and second, the creative/re-maker comes to appearance in the not necessarily fixed style of the image. Although engendering gestures remain the same regardless of the intelligible structure of the event, viz. even if the object-as-such is lengthy, Ó Maoilearca leaves room for pondering the performance of the idea as a mode of assemblage, for the latter opens the possibility of multiple performances, which potentially or actually constitute a greater compound. Since the idea is always in the making, shortness, as a part-whole relation, may be said to operate here in terms of actuality versus potentiality, as the confrontation between the film that-is versus the films that-can-be.

Along the lines of desirable tensions, media scholar Warren Buckland weaves (with poignant concision) a complex tissue of contradictions that reads as a dialectical 
characterization of the video clip qua short film. Reflecting on the visual rhetoric used in Michel Gondry's music video to Beck's song 'Deadweight' (2007), Buckland's analysis zooms in dramatically as to dwell on the confrontations between the photographic image and the relational structures organizing them. More specifically, the notions of antithesis and similarity are postulated as patterned structuring principles, as modes of relation between visual units that occur amidst the opposition between the aural coherence of the musical material and the visual fragmentation of the video clip. A passing reference to Aristotle's Rhetoric offers a starting point for a journey along intra- and intertextual connections, echoing not only classical rhetoric, but also debates on conceptual symmetry, semantic reversal and sameness versus difference - all on multiple analytical levels.

Film theorist and specialist in Lacanian theory Todd McGowan's contribution offers a reflection on the Lumière brothers' early interruption of forward-moving time through the reversal and repetition of footage. In a move that at once points to early cinema's potential to undermine capitalism's future-oriented appeal, and challenges teleological approaches to film history by disrupting its 'taken for granted' temporal progression, McGowan links the trope of the reversal to the a-temporal logic of the Lacanian drive. Drive, here, is opposed to desire as the key trait of narrative shorts (much in line with the argument he set out in his book on the topic (2011)), in a way that calls upon other conceptual confrontations - e.g. a-temporality versus temporality, or capitalist versus alternative ideological structures - that offer interesting nuances when regarded through the lens of Lacanian psychoanalysis.

Renowned early cinema scholar Tom Gunning draws on the notion of ecstases (as limit-experience and experience of limits) to explain the allure of shortness. In his article, he briefly conjures up the notion of photogénie, a term coined by Jean Epstein in 1924 (1988), to refer to intrinsically brief moments of visual attraction embedded within feature films that fall 
outside of narrative - arguably breaking through the regime of forward-moving temporality altogether, thus falling outside of time itself. Gunning discusses such disruption in terms of 'infinite variations within a logic of recurrence and regularity'. Elaborating on the flicker films of experimental film-maker and theorist Peter Kubelka, Gunning, like McGowan, reflects on cinematic's capacity to make the event-like potentiality of time perceptible to the viewer, as the author, in a move that links his piece in interesting ways to the ones that follow, ruminates on the challenge these ultra-short films pose to the viewer to 're-train' his or her 'perception to match the instantaneous rhythm of the cinematic machine'.

It is a comparable challenge that is addressed by literary and media scholar Yasco Horsman in his compelling analysis of Disney's Steamboat Willie (Iweks, 1928), the first animated cartoon with synchronized sound. Horsman argues that the animated short prompts a mode of cinematic experience that significantly departs from the one envisioned by classical apparatus theory, the paradigm that long dominated discourses on cinematic spectatorship and pleasure alike (see e.g. Rosen 1986). Instead of imagining the viewer as both physically disembodied (and at distance) and a mental projection - i.e. a subject-position formally constructed within the filmic world to be filled in by viewer - Horsman demonstrates how these early animated films, instead, synchronize the spectator with the cinematic machinery, as the recorded and disembodied 'voice' of Mickey and its machinery (that is, cinema) enters our bodies and invites us to move.

In an equally suggestive consideration on the limits of classical apparatus theory, media scholar and game studies expert Rene Glas hinges on homunculus theory, a model known in philosophy of mind and film theory as an abstraction used to explain cognitive processes to reflect on the participating viewer's engagement with the Let's Play video, i.e. relatively short YouTube clips cropped from streaming videos that document the subjective 
experience of video gaming. In film, the figure of the homunculus has been invoked to refer to fictional characters that illustrate two modes of vision simultaneously: immersive observation within the diegetic world and submissive watching from outside the fictional universe. Transposed to the Let's Play video, Glas suggests, the homunculus model may help to unravel the complex intertwinement of media technologies (plural), audio-visual artefacts, and the multi-layered engagement of distinct interactants (viewers and maker alike). Let's Play videos exhibit the gamer and maker of the audio-visual production, whose showcase embraces the screening of the avatar in motion, as well as the player's enacting presence. Here, unlike in classical (short) film experiences, the homunculus overlaps the functions of the avatar and the gamer. Thus, the fictional world of the videogame takes the back seat to the act of gaming in the Let's Play, as performance/happening, as what is shown instead of what is told.

In another essay dealing with animation, acclaimed media scholar Sean Cubitt's short but thought-provoking article focuses on the use of vector-graphics in Chris Landreth's animated short film Ryan (2004). Stressing the potential endlessness of movement afforded by vector graphics, and the challenges this poses to the need for editing (which is more or less eradicated), Cubitt makes a case for the film's paradoxical claim to realism - a status of verisimilitude not necessarily attached to the internal coherence of the fictional world, nor limited by the external affordances of the physical world. Roughly speaking, realism is the philosophical doctrine that grants reality universal and mind-independent existence, whereas ideas are considered subjective and mind-dependent. In this light, paradoxical realism can be understood as the conflation of both ontic dimensions in a single communicative event, i.e. that of the film. The realism of Ryan, Cubitt maintains, is not that of continuity of time and space that mimics human experience in the physical universe (as classical film narration and 
its seamless realism would have it), nor that of the vector's potentially endless movements that mimic human gesture as an image projection of ideas in the mind (as Ó Maoilearca would put it). Rather, the paradoxical realism of Ryan, a remake of sorts, is achieved through the film's impeded ending, i.e. the fact that it postulates itself as but one node in a network of intertextual relations between audio-visual artefacts. It is as such, the author claims, that it allows for 'the vanishing of the human into its environment, beyond psychology and objecthood'.

With Glas and Cubitt, thus, we move from an interest in the cinematic as a machine (both in the sense of a technological apparatus and dispositif, as well as in terms of the purportedly machinic quality of cinematic experience), towards a consideration of contemporary cinematics in terms of the complex networked relations it engenders, and which make up its communicative event. The two articles that follow, by media theorists Maria Poulaki and Ulrik Ekman, both make a claim for drawing on network theory, whether it be complex systems theory or theories of networking context-awareness, in order to come to a better understanding of contemporary cinematic phenomena such as the loop (Poulaki) and the snap video chat (Ekman).

As an audio-visual artefact, the loop displays an inherent tension between short and long duration, a characteristic it shares with other distinctively contemporary audio-visual phenomena that are built up out of the continuous regeneration of digital code - such as Cubitt's vector graphics and Glas' Let's Play video, as well as Isaac's demo and Verhoeff's action cam footage addressed below. Elaboration on the idea that "prolongation suggests the possibility of infinity', Maria Poulaki points towards the key roles played by endurance and interruption as characteristic features of the loop, thus offering an original way to understand its success, that is, within the framework of an aesthetic of experiential abduction. It is 
through the loop that shortness generates duration, Poulaki suggests, in a compelling reflection on the loop as emergent epiphenomenon of the network. The notion of repetition here is readdressed from the point of view of systems theory, as the author elegantly opposes film theories' common conception of reflexivity as self-reference (conjured up, in this volume, by Martin in his reflections on the relation between form and content, and by Gunning when he refers to the experimental film's dealings with its own materiality) with a notion of reflexivity that is derived from complex systems theory. The looping point, Poulaki states, 'is a moment of reflexivity, where the present reflects the past and becomes again a new starting point, in a continuous feedback between the present and the eternal'. As a result, the loop invites us to break down the notion of cinematic experience into a 'network of units' a synthesized assemblage that includes both the appearances of technologically mediated sounds and images, however repetitive or short-lived, and the time/space (and therewith identity) formations that it gives rise to. Ulrik Ekman, in a thought-provoking short essay, picks up on this suggestion in his reflection on what he calls 'ephemerals', or snap video chats, i.e. short text messaging videos whose ephemeral complexity, he states, poses 'not just minor and secondary but a major and primary challenge in contemporary cinematics'. For Ekman, snap video chats are interesting, not on account of their specific formal traits, but rather, because of the short-lived networking relations they open up. Ekman proposes the paradigm of networking context awareness to study these transient media intimacies and 'existential co-orientations' in mixed realities that engage the interactant (both a viewer and a maker) on predominantly affective planes.

The last two articles of the present issue offer the reader a glimpse into state-of-the-art audio-visual artefacts and practices. They do so from the perspective of human experience as the horizon against which the notion of duration (and therefore shortness) must be understood, 
both accentuating the decisive role of the first-person experience and the relevance of individual approaches in the happening/grasping of temporality. In her contribution, media scholar Nanna Verhoeff, in an implicitly phenomenological fashion, tackles temporality and shortness beyond quantifiable duration inasmuch as experience, in the sense of protagonist engagement, serves as grounds for understanding length. The argument takes the notion of footage as its starting point. The conventional (analogue) definition of the term as unedited film material is introduced in a lexicographical note, highlighting that its unit of measure (foots) translates duration into spatial materiality. In contrast, Verhoeff sustains that footage can be rethought beyond metric and chronometric aspects. In that account, footage would come to express a time/space intersection that blooms in the domains of personal experience. It is at this point that Verhoeff's use of Action Cam shots as a case in point displays its maximum illustrative power, as she picks up on the personal as a mode-of-address (also referred to by Ekman in this volume), and mulls over the short film experience as intervention in the field of cartography. Here, the idea of mobility echoes in the signifier 'footage' as 'the feet that "make" the walk' in the context of the visual mapping of space and digital (GPS) navigation. The notion of cartography, here, is brought into play as both a metaphor for understanding cinematic practices, and as a compound praxis that assimilates the cinematic metaphor.

Finally, in his contribution, Bruce Isaacs deals with the phenomenological aspects of digitally coding through his analysis of the demoscene. 'Demos', succinctly put, are audiovisual presentations ran on computers in real time, which gather a community of programmers, graphics artists, musicians, and enthusiasts around them. The author dwells on the peculiar experience pertaining demos and other digital artefacts. Here the dichotomy of form and code, i.e. the front-of-house presentation on the one hand, and its offstage coding on 
the other hand, stands out as a solid ground to understand aesthetic experience as reachable not only by virtue of our sensorium, but also through naked-eye decoding. This is a very topical argument - all the more interesting in light of the general claim of the article: that demos bring together both facets of experience simultaneously. Yet, it is not without thoughtprovoking intricacies. Code has a form on its own, through which it becomes graspable 'as code' (not as screening) in experience. Such form is accessible only to those familiar with it qua sign systems (not qua visual image). Therefore, claiming that the form of the demo refers to its 'materialization' on screen -in contrast with its code- is intuitively plausible, but calls for attention to the formal aspects of code. Regarding shortness, the author makes room for thinking of temporality, and hence shortness, in terms other than quantifiable duration. Gazing at the aesthetic experience of the demo 'as code' enlarges the agency of time, from a dimensional condition of perception, to a creative restraint that challenges demo makers to prove their virtues in performance.

Thus, what started off as an enquiry into the short film's most elemental features traversed into a reflection on the cinematic machinery and the machinic qualities of cinematic experience, which then turned into a deliberation of the phenomenological aspects of experiencing cinematic materiality. And what commenced as a consideration of the cinematic in terms of repetition and difference developed into a contemplation on contemporary cinematics as a compound of networked relations that hinges on the complex temporality of the ephemeral, the compressed and the infinite. It is our hope that the polyphony that emerges, in which fifteen voices are knitted together in patterns of consonance and dissonance around the notions of time, technology, perception and creativity, offers a timely contribution to the 
debates on contemporary cinematics and, as such, an intellectual stimulus to the discussions in philosophy of communication.

\section{References}

Aristotle (2010), Rhetoric (ed. W. D. Ross), New York: Cosimo Inc.

Epstein, Jean ([1924] 1988), 'On certain characteristics of photogénie', in Richard Abel (ed.), French Film Theory and Criticism: A History/Anthology, 1907-1929, Princeton, NJ: Princeton University Press, pp. 314-18.

Gondry, Michel ([1997] 2003), 'Deadweight', Directors Label Volume 3: The Work of Director Michel Gondry [DVD], New York: Palm Pictures.

Harbord, Janet (2007), The Evolution of Film: Rethinking Film Studies, Cambridge and Princeton, NJ: Polity Press and Princeton University Press.

Hesselberth, Pepita (2014), Cinematic Chronotopes: Here, Now, Me, New York, London: Bloomsbury Academic.

Iwerks, Ub (1928), Steamboat Willie, Los Angeles: Walt Disney Productions.

Landreth, Chris (2004), Ryan, Toronto: Copperheart Entertainment, Canada Council for the Arts, National Film Board of Canada (NFB)

Leth, Jørgen (1967), Det perfekte menneske/The Perfect Human, Copenhagen: Laterna Film.

Leth, Jørgen and Von Triar, Lars (2003), De fem benspcend/The Five Obstructions, Hvidovre: Zentropa Real ApS.

McGowan, Todd (2011), Out of Time: Desire in Atemporal Cinema, Minneapolis: University of Minnesota Press.

Mullarkey, John (2010), Philosophy and the Moving Image: Refractions of Reality, Houndmills, Basingstoke, Hampshire and New York: Palgrave Macmillan. 
Pöppel, Ernst (1978), ‘Time perception', in Stuart Anstis, Richard Held, Herschel W.

Leibowitz and Hans-Lukas Teuber (eds), Handbook of Sensory Physiology Vol. VIII:

Perception, Berlin: Springer-Verlag, pp. 713-729.

Rosen, Philip (ed.) (1986), Narrative, Apparatus, Ideology: A Film Theory Reader, New York: Columbia University Press.

\section{Contributors details}

Pepita Hesselberth is Assistant Professor Film and Literary Studies, Leiden University Centre for the Arts in Society (LUCAS), the Netherlands. She is the author of Cinematic

Chronotopes: Here, Now, Me (New York, London: Bloomsbury Academic, 2014). Her research interests include, besides new cinematic ontologies, time and temporality, precarity and self-precarization, new political ecologies, digital culture. Her current research project is entitled Disconnectivity in the Digital Age.

Carlos M. Roos is currently pursuing doctoral research in Communication Sciences at Ghent University, Belgium, and in Philosophy of Art at Leiden University, the Netherlands. He teaches at the Department of Media Communications of Webster University Leiden. His research interests include metaphysics of art, critical theory and comparative philosophy.

Contacts:

p.hesselberth@hum.leidenuniv.nl

carlosmiguel.roosmunoz@ugent.be 